\title{
CONTRIBUIÇÕES DE ALGUNS AUTORES DE TRÊS DAS PRINCIPAIS ESCOLAS ANTROPOLÓGICAS PARA OS ESTUDOS DO LAZER: EVOLUCIONISTA, CULTURALISTA E FUNCIONALISTA
}

Recebido em: 25/10/2011

Aceito em: 05/06/2012

\author{
Natalia Puke $e^{1}$ \\ Nelson Carvalho Marcellino ${ }^{2}$ \\ Universidade Metodista de Piracicaba - UNIMEP \\ Piracicaba - SP - Brasil
}

RESUMO: O lazer, no sentido amplo do termo, é entendido como uma manifestação cultural que estabelece múltiplas relações com os aspectos sociais e econômicos que constituem as sociedades contemporâneas. Assim, para que se tenha uma compreensão mais vasta das questões metodológicas das pesquisas relativas ao lazer e seu significado para o ser humano contemporâneo, fazem-se necessárias as contribuições teóricas de áreas do saber que possibilitem uma "diagnose" dos pontos nodais implícitos em suas manifestações, que por ora também contribuem para alienar e excluir o sujeito em detrimento de seu desenvolvimento sociocultural e ético. Partindo dessa perspectiva e problematizando o conceito de lazer relacionado aos sistemas de produção e às práticas mercadológicas, esse artigo analisa o que o processo discursivo das escolas antropológicas, evolucionista, culturalista e funcionalista tem a contribuir para os estudos do lazer.

PALAVRAS CHAVE: Atividades de Lazer. Antropologia. Sociedade.

\section{THE CONTRIBUTIONS OF THREE MAIN ANTHROPOLOGICAL SCHOOLS TO STUDIES ON LEISURE: EVOLUTIONISM, CULTURALISM, AND FUNCTIONALISM}

ABSTRACT: Leisure, in the broad sense of the term, is understood as a cultural manifestation that establishes multiple relations with social and economical aspects of contemporary societies. Thus, for a broader understanding of methodological questions related to leisure and its meaning for the contemporary human being, one must resort to theoretical contributions of some fields of knowledge that allow a "diagnosis" of nodal points implicit in its manifestation, which now contribute to alienate and exclude the subject in detriment of his social-cultural and ethical development. From that

\footnotetext{
${ }^{1}$ Graduanda em Filosofia, bolsista de Iniciação Científica pelo programa CNPq/PIBIC e membro do GPL - Grupo de Pesquisas em Lazer.

${ }^{2}$ Livre docente em Educação Física (Estudos do Lazer), docente do Mestrado em Educação Física da UNIMEP, líder do GPL - Grupo Lazer de Pesquisa em Lazer e Pesquisador do CNPq.
} 
perspective and problematizing the concept of leisure related to the production systems and market practices, this paper analyses the contributions of the discursive processes of anthropological schools, such as Evolutionism, Culturalism, and Functionalism, to the studies on leisure.

KEYWORDS: Leisure Activities. Anthropology. Societies.

\section{Introdução}

A partir de uma perspectiva genealógica ${ }^{3}$ que analisa as formas discursivas no intento de dar voz àquilo que é "silenciado" pelos meios de massa e instituições ligadas ao aparelhamento do poder - o lazer que muitas vezes é considerado um "adereço" inofensivo da vida cotidiana -, se mostra também, como um dos indicativos sintomáticos das problemáticas humanas, na medida em que se situa no entrelaçado das atividades diárias, estabelecendo múltiplas relações com os aspectos socioculturais e econômicos que constituem o funcionamento e estrutura das sociedades contemporâneas.

Nesse sentido, para que se tenha uma compreensão mais vasta das questões metodológicas das pesquisas relativas ao lazer e seu significado para o ser humano contemporâneo, as investigações não podem ficar na dependência de uma disciplina exclusiva, como por exemplo, a Educação Física, área historicamente ligada à temática. Faz-se necessário, portanto, as contribuições teóricas de outras áreas do saber que abarquem, de certo modo, a sua complexidade e tensões latentes na esfera sociocultural.

Partindo dessa perspectiva e problematizando o conceito de lazer de maneira transversal inserido nas mais diversas manifestações culturais, relacionado aos sistemas de produção e as práticas mercadológicas, esse artigo analisa bibliograficamente

\footnotetext{
3 "Genealogia quer dizer ao mesmo tempo valor da origem e origem dos valores [...] se opõe ao caráter absoluto dos valores tanto quanto ao seu caráter relativo e utilitário. Genealogia significa o elemento diferencial dos valores do qual decorre o valor destes. Genealogia quer dizer, portanto, origem ou nascimento, mas também diferença ou distância na origem” (DELEUZE, 1976, p. 4).
} 
enquanto método e processo discursivo as contribuições, de três, das principais Escolas Antropológicas para os estudos do lazer, sendo elas: Evolucionista, Culturalista e Funcionalista.

\section{O lazer}

Dada à complexidade da temática, é necessário, discorrermos, antes de adentrarmos na análise das escolas antropológicas, um pouco sobre o conceito de lazer, o contexto histórico no qual ele se fez objeto e os aspectos que o tensionam e problematizam a sua prática e atitude na esfera sociocultural, sendo eles, trabalho e consumo.

Nas últimas décadas o lazer tem sido alvo de pesquisa de diversos pesquisadores, tanto da Educação Física, como das Ciências Humanas. Os estudos contemporâneos como dos pesquisadores Dumazedier e Marcellino, permitiram compreender o lazer de forma ampla, denunciando a simplicidade descritiva na Constituição Brasileira.

Para Marcellino (2010), o lazer "transcende" a determinação constitucional ${ }^{4}$ que equivocadamente o considera como um subitem do esporte, e passa a ser compreendido, portanto, como o integral de todas as atividades, práticas, escolhas e/ou atitudes vivenciadas pelo sujeito no seu "tempo disponível".

\footnotetext{
${ }^{4} \mathrm{O}$ termo lazer aparece em algumas passagens da Constituição Brasileira que está em vigor desde 1988. No art. 6 e 7 do Capítulo II que trata dos Direitos Sociais e na Seção III que diz respeito ao Desporto. A primeira passagem o legitima como um direito legítimo de todo cidadão, mas a segunda, especificamente no art. 217 restringe e não esclarece o seu campo de atuação, caracterizando-o apenas como um subitem do esporte. Ainda, no último parágrafo do item IV é inferido que "o Poder Público incentivará o lazer, como forma de promoção social”. Disponível em: https://www.planalto.gov.br/ccivil_03/Constituicao/Constitui\%C3\%A7ao.htm

5 Segundo Marcellino (2007), o lazer é considerado "tempo disponível" em distinção a "tempo livre", uma vez que tempo nenhum pode ser considerado livre de coações morais e sociais. Além disso, a partir da sua ótica materialista-histórica o lazer emerge do conflito entre capital e trabalho. Assim, acerca dessa dialética, o lazer se constitui como uma síntese entre essas duas forças e passa a ser um direito a partir da condição da qual o cidadão já exerceu as suas obrigações sociais, ou seja, já trabalhou.
} 
O sentido etimológico de lazer nos faz compreender algumas questões que permeiam o solo no qual ele se constituiu enquanto conceito, e consequentemente, nos permite interpretá-lo e relacioná-lo mediante as transformações decorrentes na segunda metade do século XIX. Isso porque, o termo lazer advém do grego licere 6 que designa aquilo que é "lícito" e "permitido" ou ainda, o derivativo "valor"”.

Como já apontamos, sua noção conceitual passa a ser construída somente na segunda metade do século XIX, período no qual os adventos da sociedade capitalista e industrial alcançaram o seu momento de efervescência transformando as relações entre o ser humano e tempo, e, sobretudo, entre ser humano e trabalho. Esse período emblemático da história do homem ocidental é demarcado não só pelas mudanças nas esferas socioeconômicas, ou seja, nos modos de produção, mas também, pela aura de progresso evidenciada no otimismo do conhecimento científico ${ }^{7}$, pelo desenvolvimento das tecnologias e ainda, pela confluência da disciplinaridade do corpo e a sua usura para o prazer.

Segundo Corbin (1991) na virada do século XIX para o XX os indivíduos descobrem as praias como um espaço de recreação, as brincadeiras de bola como diversão e os passeios de bicicleta como possibilidade de sociabilidade. Ora, é na confluência entre a ginástica ambiciosa e as atividades lúdicas, que as práticas esportivas emanciparam-se da esfera médica e do treinamento militar, e passam a ser vivenciadas sem obrigatoriedade, na medida em que se movem em favor do bem estar

\footnotetext{
${ }^{6}$ Dicionário Eletrônico Houaiss 3.0, 2009.

${ }^{7}$ Período da Segunda Revolução Industrial ou Científico-tecnológica, no qual há a invenção dos veículos automotores, do avião, da iluminação elétrica, do telefone, do cinema, da radiodifusão, da fotografia, entre outros aparatos tecnológicos. Nesse sentido, "falar de finais do século XIX significa lembrar uma sociedade confiante em suas aquisições e marcada por uma atmosfera de fausto e luxo. Não é para menos que o termo fin de siècle tenha ficado, paradoxalmente, a esse período, assim, como a designação belle époque; duas expressões que remetem a uma só representação desse momento, que parecia alheio aos problemas graves que ameaçavam uma estrutura - aparentemente - tão sólida" (COSTA \& SCHWARCZ, 2000, p. 9).
} 
individual, da expansão de um corpo em liberdade e de sua busca pelo prazer ${ }^{8}$. É no desdobramento desses acontecimentos que o conceito de lazer passa a tomar forma, significado e institui-se no lugar do ócio ${ }^{9}$ desinteressado e contemplativo.

Além dessas referências, é neste cenário cultural, que por ora é legado até os nossos dias, que o trabalho passa a ser considerado um imperativo moral ${ }^{10}$ ordenado pelas lógicas de produção e disciplina social.

No contexto social e civilizador, o trabalho que possibilitou a ascensão do homem em relação ao determinismo biológico, é também uma atividade de alienação e castração, sobretudo, "nos sistemas onde as divisões sociais privilegiam alguns e submetem a maioria ao trabalho imposto, rotineiro e nada criativo. Ao invés de contribuir para a realização do homem, este trabalho destrói sua liberdade" (ARANHA \& MARTINS, 1991, p. 6). Cabe lembrar, portanto, que a etimologia da palavra trabalho provém do latim vulgar tripalium, que significa instrumento de tortura de três paus (JAPIASSÚ \& MARCONDES, 2006).

É diante dessas transformações decorrentes do crescimento da sociedade industrial e urbana que modificaram as relações de trabalho e hábitos culturais, que alguns intelectuais passaram a se ocupar com a temática do lazer e preconizá-lo como direito do trabalhador. Segundo Marcellino (2010) a obra "Direito à Preguiça"

\footnotetext{
${ }^{8}$ CORBIN, Alain. Gritos e Cochichos. In: PERROT, Michelle (Org.). História da Vida Privada. Da Revolução Francesa à Primeira Guerra. São Paulo: Companhia das Letras, 1991.

${ }^{9}$ No sentido usual ócio significa "cessação do trabalho; folga, repouso, quietação, vagar" (HOUAISS, 2009) e ainda, etimologicamente ócio do latim otium significa lazer, atividade intelectual ao vil negotium, isto é trabalho ou negócio (JAPIASSÚ \& MARCONDES, 2006).

${ }^{10} \mathrm{O}$ desempregado e o vadio representa um receptáculo onde se enquadra o "viveiro natural da delinquência. "O próprio sistema repressivo constitui este viveiro, formado por uns poucos grandes "malandros" e a massa de pequenos marginais ou desempregados [...]. No Código Penal de 1890, prevê apenas a punição de um certo tipo de "desordem", assimilada a "vadiagem" [...]. O artigo 402 e parágrafo único do Código Penal, inserido no capítulo que trata dos vadios e capoeiras, considera criminoso [...]". (FAUSTO, 1984, p. 35)
} 
publicada em 1883 pelo socialista Paul Lafargue $(1842$ - 1911) pode ser considerada o primeiro "manifesto" em favor do lazer dos operários. Ainda segundo Marcellino (2010), nas primeiras décadas do século XX o filósofo Bertrand Russel (1872 - 1970) mediante a obra "Elogio do lazer" de 1932, enfatizou que era somente no tempo de lazer que os operários tinham a possibilidade de desfrutar aquilo que realmente queriam.

Nesse sentido, podemos apontar acerca dessas referências históricas que o lazer encontra-se no intermédio das obrigações sociais, e é "permitido" (retomando a sua referência etimológica), visto que possibilita a compensação física do indivíduo e seu preparo mental para a próxima jornada de trabalho. Ora, se o indivíduo já cumpriu o seu papel social, ou seja, trabalhou, é legítimo e legal que ele tenha um "tempo disponível" para si, pois isso possibilita a manutenção e a docilização do corpo social. Além disso, o lazer é "lícito" (mais uma referência a etimologia), ao passo que ele se refere ao tempo em que o indivíduo está suscetível ao engodo do mercado. Comprando, consumindo e desejando a aquisição dos produtos anunciados pelos modismos o individuo contribui para a sustentabilidade da engrenagem capitalista. Assim sendo, o lazer aduz a alienação e se transforma em "trabalho" de um modo invertido, na medida em que não percebemos que mesmo fora do ambiente do trabalho continuamos trabalhando e alimentando a funcionalidade do mercado.

Segundo Marcellino o lazer massificado é representado por "práticas compulsivas, ditadas por modismos, ou denotadas de status. Além disso, é marcante a presença dos componentes de "produtividade". Valoriza-se a performance, o produto e não o processo de vivência que lhe dá origem” (MARCELLINO, 2006, p. 14).

Na sociedade capitalista onde o privado é valorizado e legítimo, o lazer também é privatizado. Percebemos que a consequência para o "rico" é a alienação e para o 
"pobre" é o difícil acesso. Ainda segundo Marcellino, os condomínios constroem o "cantinho do sonho", onde o lazer é individualizado, com a profusão de piscinas, parabólicas, bancos e jardins individuais. Além disso, as áreas de interesses intelectuais e artísticos como as bibliotecas, museus, galerias de artes e teatros, frequentemente a participação é dificultada para as pessoas com menos condições financeiras, uma vez que o acesso é inibido pelo "ar de santuário de que se revestem as construções e sua sistemática de utilização, talvez porque, e até principalmente, por não serem mantidos pelo poder público" (MARCELLINO, 2007, p. 55).

Para o mais pobres ainda há o problema das distâncias entre as unidades de morada e os "equipamentos específicos" de lazer, tais como parques, cinemas e teatros. Assim sendo, Marcellino (2007, p. 55) aponta, que "as sérias deficiências de transportes e o problema cada vez mais grave da segurança pública certamente contribuem para confinar as pessoas ao ambiente domestico". Apesar disso, o lar pode ser entendido como parte integrante dos equipamentos não-específicos de lazer, ou seja, tal com os espaços construídos não prioritariamente para essa função, mas que eventualmente podem cumpri-la. Entretanto, o desafio é transformá-lo em um ambiente propício para tal vivência do lazer, mesmo em decorrência das dificuldades que permeiam as relações familiares.

Contudo, embora o lazer possa estar atrelado ao utilitarismo capitalista tal como uma mercadoria a ser vendida, ou ainda, instrumentalizado para exclusão e alienação social, é possível conceituá-lo também, como um forte veículo para a educação e desenvolvimento sociocultural.

Retomando o seu significado etimológico, o lazer atribuí "valor" para o desenvolvimento ético e social do sujeito, uma vez que sendo ele o "tempo disponível" 
é através dele que se encontra a possibilidade de escolha e usura do tempo e espaço existente.

Acerca dessa problemática que constata as contradições que envolvem a temática, é preciso muita seriedade das políticas públicas de fomento do lazer, e ainda, é imprescindível educar "para" e "no" o lazer, para que ele não seja um espaço restrito a manipulação social ou privação e sim, um "lugar reinventivo", em que o sujeito encontre a possibilidade de prazer e liberdade que lhe são privados quando imersos na rotina do trabalho e das obrigações sociais.

Desse modo, segundo Marcellino (2007) o lazer pode ser compreendido conceitualmente como,

\footnotetext{
Cultura vivenciada (praticada, fruída ou conhecida), no tempo disponível das obrigações profissionais, escolares, familiares, sociais, combinando os aspectos tempo/espaço e atitude [...]; tempo a ser privilegiado para a vivência de valores que contribuam com mudanças de ordem moral e cultural [...]; portador de um duplo aspecto educativo, veículo e objeto de educação, considerando, assim, não apenas as suas possibilidades de descanso e divertimento, mas também de desenvolvimento pessoal e social (MARCELLINO, 2007, pp. 46 - 47)
}

Para Marcellino (2006) as atividades praticadas no tempo de lazer podem ser revestidas por seis conteúdos culturais: Físico-esportivo (exercícios), social (festas), artístico (estética), manual (artesanato), intelectual (leitura/palestras) e turístico (passeios). Segundo o autor, vivenciar "idealmente" o lazer seria "exercitar, no tempo disponível, o corpo, a imaginação, o raciocínio, a habilidade manual, o contato com outros costumes e o relacionamento social, quando, onde, com quem e da maneira que quisesse" (MARCELLINO, 2006, pp. 18 - 19).

Apesar dessa caracterização, o lazer não corresponde somente e necessariamente a uma ocupação ativa, ou seja, uma prática. Ele também pode ser compreendido como 
Natalia Puke e Nelson C. Marcellino Contribuições de Alguns Autores das Três das Principais Escolas...

uma atitude, isto é, um posicionamento do sujeito para o ócio se esta for uma escolha (MARCELLINO, 2010).

Acerca dessas proposições podemos concluir que é na confluência dos conflitos entre o humano e trabalho, humano e tempo e humano com o próprio corpo que o conceito de lazer passa a ter lugar na sociedade e na cultura.

\section{A antropologia}

Partindo dessas referências podemos iniciar a discussão sobre as escolas antropológicas. Cabe, portanto, elucidar brevemente que a antropologia surge na Europa, na segunda metade do século XIX, período no qual o homem não é mais visto só como sujeito, mas também como objeto do saber. Rupturas no campo do conhecimento, como a emancipação do pensamento filosófico em relação ao metafísico, e, sobretudo, a predominância das concepções das ciências empíricas (física, biologia e química) sobre o entendimento bio-psico-social, confluem para rupturas de paradigmas, que além de provocarem um giro epistêmico na conceituação do que é o homem, transformam também, as relações culturais em todas as instâncias no "mundo" ocidental.

É nesse movimento que os estudos antropológicos, propõem, mediante uma visão naturalista, "um novo modo de acesso ao homem, que passa a ser considerado em sua existência concreta, envolvida nas determinações de seu organismo, de suas relações de produção, de sua linguagem, de suas instituições, de seus comportamentos" (LAPLANTINE, 2007, p. 55).

Os primeiros antropólogos tinham como objeto de investigação apenas as sociedades exteriores às européias e norte-americanas. Seus interesses delimitavam-se, 
portanto, aos estudos comparativos entre as culturas ditas "civilizadas" e "selvagemprimitivas", na pretensão de encontrar, uma origem comum entre as distintas culturas. Entretanto, no processo do seu desenvolvimento como saber independente, o olhar antropológico passou a abordar também, além das sociedades tribais, as urbanas, no intento de estudar o homem "inteiro" nas suas relações com tudo aquilo que o constitui enquanto o humano, isto é, os modos de produção econômica, as técnicas, a organização política e jurídica, os sistemas de parentesco, conhecimento, religião, linguagem, psicologia e artes.

\subsection{O evolucionismo e o lazer}

Os primeiros antropólogos vinculam-se ao evolucionismo cultural e segundo alguns antropólogos contemporâneos, tais como Castro (2009) e Laplantine (2007), eles são representantes da "antropologia de gabinete", que é o estudo baseado em relatos sem evidência científica, construído através da coleta de relatos feita por missionários, comerciantes, viajantes ou observadores superficiais, e não mediante um levantamento etnográfico empírico junto a cultura e linguagem das sociedades investigadas.

Embebidos pelo "espírito" progressista do século XIX e influenciados pelos estudos das ciências biológicas - predominante em termos de matriz nos saberes do século XIX -, e sobretudo, pela abordagem positivista ${ }^{11}$ da história, os antropólogos evolucionistas compreendem o processo histórico cultural hierarquizado em estágios, que por sua vez, se desenvolve linearmente a partir de uma única origem e para uma finalidade uníssona - o progresso civilizatório.

11 “A característica do Positivismo é a romantização da ciência, sua devoção como único guia da vida individual e social do homem, único, conhecimento, única moral, única religião possível. Como romantismo em ciência, o Positivismo acompanha e estimula o nascimento e a afirmação técnicoindustrial da sociedade moderna e expressa a exaltação otimista que acompanhou a origem do industrialismo" (ABBAGNANO, 2007, p. 776). 
A perspectiva evolucionista em antropologia baseia-se fundamentalmente no seguinte raciocínio: "reduzir as diferenças culturais a estágios históricos de um mesmo caminho evolutivo" (CASTRO, 2009, p. 27). Nesse sentido, todas as culturas devem obrigatoriamente desenvolver-se pela seguinte ordem evolutiva: da selvageria à barbárie até a civilização.

Segundo o antropólogo francês Laplantine (2007), a preocupação desses antropólogos era de uma prática extensiva do tempo e espaço, ao invés de intensiva em relação às fatos particulares. Nesse sentido, o objetivo não era compreender as especificidades das diversas culturas consideradas primitivas, mas sim, encontrar os exemplos etnográficos que pudessem "ilustrar o processo grandioso que conduz as sociedades primitivas a se tornarem sociedades civilizadas" (LAPLANTINE, 2007, p. 70). É por isso que os interesses dos evolucionistas delimitavam-se aos estudos comparativos, enquanto método, entre as culturas ditas "civilizadas" e "selvagens/primitivas", ao passo que intuíam entender a história passada das grandes civilizações.

Inserido na abordagem discursiva evolucionista encontramos o norte-americano Lewis Henri Morgan (1818 - 1881). Segundo Laplantine (2007), entre os evolucionistas ele é o que apresenta menos rigidez doutrinal, talvez porque, contrariamente aos demais, ele tenha convivido empiricamente com as culturas ditas "primitivas".

Entre as suas principais obras encontramos "A Liga dos Iroquês" de 1851 (CASTRO, 2009). Nesta Morgan teve o objetivo de "encorajar um sentimento mais bondoso em relação aos índios, baseando num conhecimento mais verdadeiro de suas instituições civis e domésticas, e de suas capacidades de futura elevação" (MORGAN $^{12}$

\footnotetext{
${ }^{12}$ MORGAN, Lewis H. (1877). A Sociedade Primitiva. Lisboa: Editorial Presença, 1973.
} 
apud CASTRO, 2009, p. 10). Viajando pelo mundo, observando as diversas culturas e coletando informações ele sistematizou a teoria em que o parentesco e a descendência definiriam as relações sociais. Segundo Castro (2009), encontramos essa teoria no livro "Sistemas de Consanguinidade e afinidade da família humana" de 1871, que veio contribuir posteriormente para os estudos sobre os laços sociais e pactos de sangue.

Em seu livro "A sociedade Primitiva" de 1877, analisado neste artigo, ele estudou os estágios e processos das sociedades humanas: aborígenes australianos, índios iroquês, astecas, gregos e romanos.

Segundo Morgan (1973), as épocas de real progresso estão conectadas as artes de subsistência, que incluem a ideia darwiniana "de luta pela existência". Ele destaca também, que o curso da história humana procede ao plano de uma "Inteligência Suprema" para desenvolver o selvagem em civilizado, passando pelo bárbaro. Entretanto, com o decorrer do processo histórico o direito divino está sendo trocado pelo direito do progresso.

Em seu sistema antropológico o caminho da evolução seria natural e necessário, e consequentemente, caracterizaria o monogenismo das raças. Assim,

A história da humanidade é uma só quanto à sua origem, uma só quanto a experiência e uma só quanto ao seu progresso [...] A raça humana, pelo facto de ter tido a mesma origem, seguiu percursos idênticos, tomando veredas diferentes mas paralelas em todos os continentes [...] A humanidade iniciou a sua carreira no ponto mais baixo da escala, abrindo caminho, do estado selvagem até à civilização, através da lenta acumulação do conhecimento empírico [...] (MORGAN, 1973, pp. 7 - 8 - 9 - 13).

Além disso, de acordo com a sua concepção, haveria uma uniformidade das operações da mente. Nesse sentido,

As invenções e descobertas estão em direta relação com o progresso da humanidade, assinalando sua marcha por uma série de etapas sucessivas, ao posso que as instituições sociais e civis, dada a relação 
com as necessidades permanentes do homem, se desenvolveram a partir de alguns germes originais de pensamento" (MORGAN, 1973, p. 8).

Em síntese os processos de evolução que correspondem à formação gradual da civilização passam consecutivamente pela: Subsistência, Governo, Linguagem, Família, religião, vida doméstica e arquitetura, e por fim, a propriedade. Nesse sentido, o autor aduz que a ideia da propriedade demarca o começo da civilização, ao passo que "ela levou a humanidade não só a vencer os obstáculos que retardavam a civilização, mas também a fundar a sociedade política baseada na base do território e da propriedade" (MORGAN, 1973, p. 16).

Para Morgan (1973) os períodos do processo evolutivo correspondem ao tempo imaterial e são classificados como: período inicial (selvageria), intermediário (barbárie) e final (civilização). Assim, as condições de sobrevivência desenvolvidas nesses períodos são determinadas pelo fato material e caracterizados, portanto, mediante a valoração dos status, sendo eles: inferior (selvageria), intermediário (barbárie) e superior (civilização).

Acerca dessa perspectiva todas as culturas deverão obrigatoriamente, passar por esses períodos e condições. Todas as culturas que nunca alcançaram a arte da cerâmica são consideradas selvagens e as que nunca alcançaram o alfabeto fonético e o uso da escrita, são classificadas como bárbaras. Segundo o autor, "os antepassados das tribos gregas, romanas e germânicas passaram pelos estágios que indicamos, e, na metade do último, a luz da história caiu sobre eles" (MORGAN, 1973, p. 29).

Nessa citação ele assinala implicitamente a superioridade das sociedades européias em relação às demais e afirma, portanto, a ideia de uma verdade, de um referencial e apogeu cultural a ser alcançado, neste caso, as sociedades européias. 
Dialogando com essas concepções encontramos o escocês James George Frazer (1854 - 1941) um dos mais dogmáticos antropólogos evolucionistas.

No texto "O Escopo da Antropologia Social", que veio a se tornar, em 1908, um marco da antropologia social quando fora apresentado em uma palestra em Liverpool, Frazer, teve como objetivo - "descobrir as leis gerais às quais se possa presumir que os fatos particulares se conformam” (FRAZER, 2009, p. 103 - 104). Segundo ele,

Os negócios do homem, por mais complexos e incalculáveis que possam parecer, não são exceção à uniformidade da natureza. Portanto, a antropologia, no sentido mais amplo da palavra, visa a descobrir as leis gerais que regularam a história humana no passado e que, se a natureza for realmente uniforme, é de se esperar que a regulem no futuro (FRAZER, 2009, p. 104).

Para Frazer, "a humanidade, como bem se tem dito, avança em escalões, isto é, em colunas que marcham não uma ao lado da outra, mas em linhas dispersas, cada uma num grau diferente de atraso com relação ao líder” (FRAZER, 2009, p. 116). Assim sendo, ainda sob suas palavras,

Os homens de uma mesma geração diferem enormemente quanto à capacidade e aos valores inatos. Nenhuma doutrina abstrata é mais falsa e pérfida que a da igualdade natural dos homens [...] Os verdadeiros governantes dos homens são os pensadores que fazem avançar o conhecimento [...] Os descobridores de novas verdades são os verdadeiros reis da humanidade (FRAZER, 2009, pp. 113 - 114).

Neste artigo Frazer (2009) declara explicitamente a sua desconsideração em relação ao conhecimento popular e em contrapartida, a exaltação cientificista pautada no uso da razão: A multidão ignorante e insensata agarra-se, com sombria
determinação, a crenças muito toscas que realmente respondem a
textura mais grosseira de seus intelectos subdesenvolvidos. Assim,
enquanto o credo professado pela minoria esclarecida está
constantemente mudando sob a influência da reflexão e da
investigação, o credo real, embora não declarado, da massa da
humanidade parece ser quase estacionário, e a razão por que se altera
tão pouco é que, na maioria dos homens, sejam eles selvagens ou seres 
aparentemente civilizados, o processo intelectual, de tão lento, é quase imperceptível (FRAZER, 2009, pp. 118 - 119).

Sua perspectiva em relação aos povos considerados "primitivos" é hostil e pejorativa. Segundo ele, "o selvagem é um documento humano, um registro dos esforços do homem para se elevar acima do nível da besta” (FRAZER, 2009, p. 121). Nesse sentido,

Em comparação com o homem civilizado, o selvagem representa um estágio estacionado, ou melhor, retardado do desenvolvimento social, e, portanto, um exame de seus costumes e crenças fornece o mesmo tipo de evidência da evolução da mente humana que o exame de um embrião fornece da evolução do corpo humano. Em outras palavras um selvagem está para um homem civilizado como uma criança está para um adulto; [...] (FRAZER, 2009, p. 107).

Em "O Ramo de ouro" de 1911, outra obra analisada neste artigo, Frazer "realiza a melhor síntese de todas as pesquisas do século XIX sobre as "crenças" e “superstições"” (LAPLANTINE, 2007, p. 68). Dedicando-se também aos estudos clássicos de autores gregos e romanos, nesta obra, ele legou para os estudos antropológicos importantes contribuições a respeito das religiões, mitologia e tabus. Segundo Castro (2009) seus estudos até chegaram a ser utilizados por Freud em "Totem e Tabu", mas alguns anos mais tarde, em meados dos anos 1920, esta obra, "O Ramo de Ouro", caiu no desuso, pois passou a ser considerada mais literária do que científica.

Frazer considerava que as crenças podem ser entendidas pelas seguintes etapas sucessivas e evolutivas: da magia a religião, da religião a ciência. A magia representaria uma fase anterior e mais grosseira da história do "espírito humano" e a ciência o ápice.

Apesar do seu dogmatismo etnocêntrico e cientificista, podemos encontrar também, nesta obra, um estudo panorâmico das cerimônias festivas dos povos gregos da antiguidade arcaica. Cabe salientar, que as festas e rituais campestres estavam relacionados à agricultura, ao passo que nesse período, a economia dependia do cultivo 
do solo. Portanto, as festas celebravam a colheita e a fecundidade da terra para que dela se pudesse colher os alimentos para a sobrevivência.

Frazer (1982) descreve as festas em celebração as deusas da agricultura Deméter (mãe) e Perséfone (filha). De acordo com a sua leitura, a primeira representava o cereal velho, já colhido e usufruído no ano passado e, a segunda, o cereal novo que viria a ser colhido no ano seguinte. Nessas festas os fieis gritavam: “Chuva, concebei!”. Nesse sentido, como a divindade representa o cereal, quando este era comido, se transformava em um sacramento.

Segundo o autor, até mesmo as festas nacionais e urbanas patrocinadas pelo Estado, "apesar de toda a sua pompa e esplendor, eram meras cópias ampliadas e embelezadas dos ritos e cerimônias simples realizados pelos camponeses em campos abertos, em celeiros e eiras" (FRAZER, 1982, p. 140).

O autor elucida também, os grandes mistérios de Elêusis, ou seja, jogos celebrados ao fim da longa seca do verão e antes das primeiras chuvas de outono. Segundo Frazer (1982), os ritos eleusínios parecem ter relação com as festas em adoração à Deméter e Perséfone, e por incluírem disputas atléticas e musicais podem até ter constituído o núcleo original dos jogos olímpicos.

O que é interessante salientar a respeito desses jogos é que os vencedores eram recompensados com medidas de cevada e que a disputa entre os ceifadores não pareciam ser puramente competições atléticas, pois, segundo Frazer,

Seu objetivo não é simplesmente de demonstrar mais forma, atividade ou habilidade dos vencedores, mas assegurar, para determinada fazenda, a posse da florescente virgem dos grãos do ano, considerada como a personificação do grão vigoroso, e transferir para vizinhos menos hábeis a idosa mãe dos grãos do ano passado, considerada como a materialização das energias já gastas e esgotadas dos grãos (FRAZER, 1982, pp. 141 - 142). 
Embora essas festas e jogos estivessem revestidos por um caráter ritualístico, tal como aponta Frazer, podemos estabelecer, de certa forma - assumindo o anacronismo -, uma estreita relação com o lazer, que no mundo contemporâneo se apresenta ligado as relações de trabalho e que por ora é vivenciado como um "escapamento" da rotina.

Dentro da concepção evolucionista, a humanidade teria apenas uma trajetória, portanto, não haveria espaço para as diversidades e especificidades culturais. Acrescento, portanto, que no final do século XIX, os europeus certos que viviam o apogeu da civilização, contatavam as sociedades "exteriores" com a pretensão de convertê-las aos seus hábitos e perspectivas culturais. Desse modo, "o evolucionismo aparece logo como justificação teórica de uma prática: o colonialismo" (LAPLANTINE, 2007, p. 69).

Nesse sentido, o discurso evolucionista, caracterizado por uma concepção eurocêntrica da cultura, favorece as formas e perspectivas elitistas, bem como, as práticas de dominação social que até mesmo o lazer está sujeito. Podemos inferir com certa cautela, que atualmente os Estados, bem como algumas instituições de fomento e desenvolvimento do lazer produzem o que podemos a nomear de "lazer de gabinete", ao passo que pretensiosamente inserem pacotes de atividades ou até mesmo, constroem áreas de recreação sem consultar as especificidades das determinadas comunidades que virão a usufruir desses recursos.

Como citam Cavalleiro \& Salgado (1996, p. 109),

No campo da difusão cultural, uma das ações que comumente encontramos são os "pacotes" de lazer, onde em alguns casos, a cultura do lazer é reduzida, ou ao supérfluo (se justificando exclusivamente pelo divertimento) ou aos padrões do mercado, ou melhor, da indústria cultural. 
Entendendo que todo lazer e cultura envolvem um campo simbólico, que incorpora valores que vão além do divertimento e do descanso - as pesquisadoras que atuavam na diretoria de Esporte e Lazer na prefeitura de Diadema- SP -, acentuam que as políticas públicas de lazer devem exercer as liberdades urbanas e se questionar "para quem, a favor de quem e com quem" os projetos estão sendo desenvolvidos. Elas inferem, portanto, que é preciso romper com "a lógica bastante corrente da população, que espera um "pacote" de lazer baixado dos "gabinetes técnicos"” (CAVALLEIRO \& SALGADO, 1996, p. 112), pois, a "relação de orgulho e prazer vividos por uma determinada comunidade são questões que permanecem para além das administrações, que extrapolam o público, e efetivamente tornam-se "comunitárias"” (CAVALLEIRO \& SALGADO, 1996, p. 112).

Acerca dessa perspectiva os projetos de lazer devem partir das diferentes manifestações, interesses, produções culturais e aspirações dos grupos que compõem uma determinada comunidade. Nesse sentido, deve-se utilizar a ação comunitária como uma alternativa operacional dentro de políticas de ação social, buscando integrar esforços "de grupos populares da cidade, atuando a partir de suas manifestações culturais, considerando os níveis de participação, e procurando através de uma política de animação superar esses níveis sem descaracterizá-los” (MARCELLINO13, 1990 apud CAVALLEIRO \& SALGADO, 1996, p. 111).

Sendo o lazer um direito de todos os cidadãos, é compromisso das políticas dos Estados e prefeituras desenvolverem ações voltadas para a construção da cidadania cultural que possibilite consequentemente,

\footnotetext{
${ }^{13}$ MARCELLINO, N. C. Subsídios para uma política de lazer: o papel da administração municipal. In: Revista Brasileira de Ciências do Esporte, v. 2I, n. 3, São Paulo, 1990.
} 
A produção de novos direitos e a multiplicação dos espaços e práticas democráticas na sociedade local, a partir de um conjunto de vivencias individuais e coletivas fundadoras de valores, símbolos, idéias, práticas, objetos e comportamentos diferenciados e diversos (CAVALLEIRO \& SALGADO, 1996, p. 102).

\subsection{O funcionalismo e o lazer}

Mais complexo que a abordagem evolucionista, encontramos o discurso funcionalista, que por sua vez fundamenta-se basicamente na possibilidade de estabelecer uma relação da análise social ao funcionamento dos sistemas biológicos. A sociedade organizada e constituída por partes inter-relacionadas se comportaria tal como um organismo biológico. Nesse sentido, a teoria da cultura funcionalista tem uma posição baseada no fato biológico e físico, pois se fundamenta na premissa que os seres humanos são uma espécie animal e por isso, estão sujeitos a "condições elementares que têm de ser atendidas de modo que os indivíduos possam sobreviver, a raça continuar e os organismos em conjunto ser mantidos em condições de funcionamento" (MALINOWSKI, 1970, p. 42).

Para cobrir teoricamente esta perspectiva antropológica analisamos o polonês Bronislaw Malinowski (1884 - 1942) e o inglês Alfred Reginald Radcliffe-Brown (1881 - 1955) - que contrariamente aos evolucionistas - apresentam uma perspectiva relativista da cultura e defendem que a antropologia deve ser uma análise decorrente do contato real com os nativos.

Esses antropólogos apresentam concepções distintas sobre o conceito de cultura e função. Embora Radcliffe-Brown nunca tenha se nomeado funcionalista, é possível relacioná-lo a teoria funcional, uma vez que seus escritos fazem pertinentes análises sobre os conceitos de estrutura e função. 
Natalia Puke e Nelson C. Marcellino Contribuições de Alguns Autores das Três das Principais Escolas...

No livro "Uma Teoria Científica da Cultura" publicado originalmente em 1922 (MALINOWSKI, 1970), o objetivo geral de Malinowski é "definir de acordo com os princípios de relevância, os elementos de uma cultura que podem ser considerados reais e de significação" (MALINOWSKI, 1970, p. 46).

Para o autor todas as culturas têm como principal denominador comum um conjunto de tipos institucionais (família, a religião, educação, economia e política), que por sua vez correspondem aos aspectos que organizam e permitem a funcionalidade de uma dada sociedade. Nesse sentido, a instituição é entendida por Malinowski como a legítima unidade da análise cultural e não possui somente um corpo material, mas também, um estatuto legal e simbólico.

Toda estrutura de uma instituição é regulada por um estatuto que sempre "corresponde a um desejo, a um conjunto de motivos, a um objetivo comum, consubstanciado na tradição ou concebido pela autoridade tradicional" (MALINOWSKI, 1970, p. 151). Além disso, o estatuto representa um sistema de valores para a consecução dos quais os seres humanos se organizam ou filiam-se as organizações já existentes. Entretanto, “o estatuto varia de comunidade para comunidade, mas é uma peça de conhecimento que pode ser obtida em pesquisa campo e que define a instituição doméstica em cada cultura" (MALINOWSKI, 1970, p. 151).

Os grupos se relacionam através de um contrato social, ou seja, pela organização. Essa organicidade deve ser reproduzida, pois, "a ordem e a lei devem ser mantidas, uma vez que a cooperação é a essência de toda realização cultural" (MALINOWSKI, 1970, p. 43). Assim, segundo Malinowski (1970) as pessoas que compõe o grupo obedecem às regras técnicas de seu status ou ofício, a regras sociais de 
etiqueta, considerações de costume, assim como também, os costumes legais, religiosos e morais que enformam o comportamento.

O conceito de cultura para Malinowski (1970, p. 46) é "um conjunto integral de instituições em parte autônomas, em parte coordenadas" e "deve ser compreendido como um meio para um fim, isto é, instrumentalmente e funcionalmente" (MALINOWSKI, 1970, pp. 69 - 70). Nesse sentido, o conceito de cultura está atrelado ao conceito de função, pois sendo a cultura uma criação artificial, ela se apresenta como um aparato instrumental que possibilita o homem a lidar com a hostilidade do ambiente natural e a atender as necessidades "através da criação de artefatos, organização em grupos cooperativos e também do desenvolvimento do conhecimento: do sentido de valor e ética" (MALINOWSKI, 1970, p. 43).

O conceito de função é um artifício heurístico para elucidar a sua teoria e sua definição está estritamente relacionada à noção de necessidade, ao passo que em todas as atividades humanas "verificamos que o uso de um objeto como parte de um comportamento técnico, legal ou ritualmente determinado leva os seres humanos a satisfação de alguma necessidade" (MALINOWSKI, 1970, p. 144). Nesse sentido,

A função sempre significa, por conseguinte, a satisfação de uma necessidade, do mais simples ato de comer à ação sacramental na qual comungar está relacionado a todo um sistema de crenças determinado por uma necessidade cultural de unificação com o Deus vivo (MALINOWSKI, 1970, p. 148)

Contudo, ele distingue as necessidades básicas (metabolismo, reprodução, confortos corporais, segurança, movimento, crescimento e saúde) das necessidades culturais ou derivadas (aprovisionamento, parentesco, abrigo, proteção, atividades, treinamento e higiene). 
As necessidades básicas são "as condições ambientais e biológicas que devem ser preenchidas para a sobrevivência do individuo e do grupo" (MALINOWSKI, 1970, p. 76). Segundo o autor há um impulso que é fundamentalmente determinado pelo estado fisiológico do organismo e pode ser esquematizado pelo seguinte sequência vital: Impulso, ato e satisfação. Para uma melhor clareza desse esquema cabe um exemplo: Fome = impulso; Busca pelo alimento = ato; Absorção do alimento = satisfação.

Fundamentando-se na psicologia behaviorista de Skinner (1904 - 1990) Malinowski (1970) aponta que o comportamento humano não está alheio aos estímulos externos provenientes do contexto cultural. Doravante, apesar dessa sequência vital (impulso, ato e satisfação) suscite biologicamente no organismo, "nem mesmo a necessidade mais simples, nem ainda a função fisiológica mais independente de influências ambientais, pode ser considerada intocada pela cultura" (MALINOWSKI, 1970, p. 77).

Nesse sentido, todas as necessidades básicas apresentam respostas culturais ou derivadas como, por exemplo: Para a manutenção do metabolismo cria-se o aprovisionamento (prover-se, abastecer-se); para reprodução o parentesco; para os confortos corporais o abrigo; para a segurança a proteção; para os movimentos as atividades; para o crescimento o treinamento e para a saúde a higiene.

A cultura como novo padrão de vida impõe também novos imperativos ao comportamento humano, ao passo que cria um tipo secundário de determinismo. Isso Malinowski nomeia de "imperativos instrumentais" (atividade econômica, normativa, educacional e política) e "imperativos integrativos" (conhecimento, religião e recreação). 
Os imperativos instrumentais gerem a organicidade de um determinado grupo, tribo ou Estado. Já os imperativos integrativos dizem sobre o simbolismo, que "na sua natureza essencial é a modificação de um organismo original que possibilita a transformação de uma tendência fisiológica em um valor cultural” (MALINOWSKI, 1970, p. 124).

O antropólogo Radcliffe-Brown apresenta uma concepção distinta do conceito de função e discorre que ele é apenas uma hipótese, uma vez que considera que toda matéria impressa pelos antropólogos é circunstancial. Entretanto, compartilha da mesma metodologia de Malinowski, pois compreende a antropologia social como uma ciência teórico-natural da sociedade humana, isto é, como uma investigação dos fenômenos sociais através de métodos essencialmente semelhantes empregados nas ciências físicas e biológicas.

Ele aponta ainda na obra "Estrutura e Função na Sociedade Primitiva” publicada em 1952 (RADCLIFE-BROWN, 1973) que a escola funcional não existe, ela é um mito inventado irresponsavelmente por Malinowski. Nesse sentido, ele salienta que não há significação alguma relacioná-lo como seguidor de Boas ou predecessor de Malinowski, ao passo que o único sentido dessa relação é simplesmente cronológico.

Para o autor não há lugar para ortodoxias ou heterodoxias nas ciências, uma vez que os trabalhos dos pesquisadores devem se desenvolver através da cooperação. Portanto, não cabe fazer discípulos, doutrinas ou escolas.

A antropologia social, segundo Radcliffe-Brown (1973) é um ramo da sociologia comparada e tem como principal objetivo determinar generalizações admissíveis mediante um esquema de interpretação aplicável que consiste em "um conjunto de 
Natalia Puke e Nelson C. Marcellino Contribuições de Alguns Autores das Três das Principais Escolas...

conceitos analíticos, que devem ser claramente definidos em relação com a realidade concreta conservando uma mútua conexão lógica” (RADCLIFFE-BROWN, 1973, p. 9).

Nesse sentido, a antropologia social não seria um estudo da cultura e sim uma investigação das formas de associação que se encontram entre os seres humanos. Desse modo, a cultura, pode ser compreendida como "o processo e meio pelo qual uma pessoa adquire conhecimento, especialidade, ideias, crenças, gostos e sentimentos, mediante contato com outras pessoas, ou pelo trato com outras coisas, tais como livros ou obras de arte" (RADCLIFFE-BROWN, 1973, p. 14).

As formas de associação entre os seres humanos integram-se ao sistema social, que por sua vez é conceituado como uma "determinada forma de vida social, em que existem relações de interconexão e interdependência, ou na expressão de Comte, relações de solidariedade entre vários aspectos” (RADCLIFFE-BROWN, 1973, p. 15).

Contudo, essa definição é insuficiente para compreender sua leitura antropológica. Portanto, é preciso elucidar três conceitos que estão logicamente interrelacionados e que constituem o sistema social, sendo eles: processo, estrutura e função.

O processo seria a própria cultura, mas que por si mesma não diz nada e por isso se manifesta pelas ações e interações sociais. Isso o autor compreende como aspectos gerais da vida, ou seja, como as formas que constituem o sistema social.

A estrutura é uma rede de relações socialmente existentes que se refere a uma espécie de ajuste ordenado das partes ou dos componentes, ou seja, pelas atividades e pessoas. Essa rede de relações não se mantém por conjunções acidentais entre os indivíduos, mas por determinações do próprio processo social, isto é, por normas, regras ou padrões. Nesse sentido, a lei se integra como parte da maquinaria da estrutura social. 
A estrutura é continua embora as partes mudem. Para tal elucidação ele faz a distinção entre estrutura social e forma estrutural. Embora a estrutura constituída pelas pessoas mude com o passar do tempo por conta dos nascimentos, mortes, emigrações, a forma estrutural pode permanecer relativamente constante, mesmo que uma determinada sociedade passe por revoluções ou sofra conquistas militares de sociedades externas.

Por fim, a sua conceituação de função segue a noção de Durkheim, na medida em que ele a considera como um modo padronizado de agir ou pensar relacionado com a estrutura social. Assim, no seio da organização social cada pessoa tem uma função.

Para evitar a ambiguidade do conceito de função e a possibilidade de uma interpretação teleológica, o autor substitui o termo necessidade, inserido por Malinowski, por condições necessárias de existência. Nesse sentido, sendo a vida social da comunidade definida aqui como funcionamento da estrutura social, a função por sua vez, permite a continuidade de sua estrutura.

Neste momento da discussão cabe salientar que o autor faz uma distinção entre pessoa e indivíduo. Embora todo ser humano que viva em sociedade seja as duas coisas, pessoa se refere a um complexo de relacionamentos sociais (membro de uma associação, cidadão ou trabalhador). Já indivíduo é um organismo biológico, onde ocorrem ações e reações fisiológicas e psicológicas e processos de transformação.

Parte da estrutura social são todas as relações de pessoa a pessoa (diádica), como por exemplo, as relações de parentesco. Entretanto, ele inclui também nessa estrutura as classes diferenciadas pelo desempenho social, que neste caso, são distinguidas por: mulher, homem, chefe ou empregado, entre outros papeis sociais. 
Acerca dessas proposições, a estabilidade, reprodução e continuidade do sistema social são análogas ao sistema orgânico e dependem da adaptação interna do indivíduo (processos fisiológicos) e externa (meio no qual o organismo vive). Assim sendo, ainda há três aspectos do seu sistema total: adaptação ecológica no qual a vida social é ajustada ao ambiente físico; adaptação social que se refere às disposições institucionais pelas quais a vida social é ordenada; e adaptação cultural que diz respeito a aquisição de hábitos e características mentais pelo indivíduo que consequentemente o habilitam a participar das atividades sociais. Em síntese "a vida social e adaptação social implicam, portanto, no ajustamento da conduta de organismos individuais às exigências do processo pelo qual a vida social continua" (RADCLIFFE-BROWN, 1973, p. 19).

Concluindo, o conceito de função orgânica é aquele que designa a "correlação entre a estrutura de um organismo e o processo vital desse organismo" (RADCLIFFEBROWN, 1973 p. 22), portanto, é uma referência teórica que cabe aos sistemas sociais. Contudo, a ruptura entre o orgânico e social se dá quando percebemos que um organismo animal não muda seu tipo estrutural no curso da vida. Como exemplifica Radcliffe-Brown, o porco não se torna hipopótamo com o passar dos anos, entretanto, a sociedade muda o seu tipo estrutural ou ainda pode ser absorvida como parte integral de uma sociedade mais vasta, como por exemplo, a dominação branca sobre os povos indígenas.

Acerca dessas proposições inferidas por Malinowski e Radcliffe-Brown e relacionadas com conceituação que fizemos anteriormente sobre o lazer, na qual o definimos como uma manifestação cultural - podemos considerá-lo uma função?

Como pudemos observar, segundo os axiomas gerais do funcionalismo de Malinowski (1970), a cultura é um integral na qual todos os elementos são 
interdependentes e atendem uma necessidade. Em síntese, toda construção cultural é instrumental e funcional, pois compreende "um sistema de objetos, atividades e atitudes, no qual cada parte existe como um meio para um fim” (MALINOWSKI, 1970, p. 140). A partir das suas concepções o lazer seria um imperativo integrativo e como cultura seria uma função ou um instrumento. Mas uma função e instrumento para quê e para quem?

Marcellino (2010) dedica algumas páginas ao que ele veio a chamar de "As abordagens funcionalistas do lazer". Segundo o autor a visão funcionalista do lazer se opõe em primeira instância ao ócio, no sentido de "parar para pensar", o que evitaria a tensão existencial que "seria necessária para a percepção da problemática individual e social" (Marcellino, 2010, p. 36). Nesse sentido, ele caracteriza ainda, que uma abordagem funcionalista pode ser moralista, romântica, compensatória e utilitarista.

Consideramos todas essas observações de Marcellino pertinentes para a discussão da temática do lazer. Entretanto, gostaríamos ainda de pensar a funcionalidade do lazer a partir da própria intencionalidade do sujeito que viria dele desfrutar. Nesse sentido, há a possibilidade de pensar a função do lazer não apenas integrada a estrutura social e capitalista, mas também re-significada "pelo" e "a partir" do próprio sujeito.

Para Malinowski a cultura em todos os seus âmbitos é fundamentalmente uma função, ao passo que invariavelmente atende uma necessidade. $O$ conceito de necessidade, neste caso, relaciona-se a um impulso orgânico ou cultural que precisa ser satisfeito. Assim sendo, pensamos que é possível compreender o lazer como a possibilidade dessa satisfação ser atendida. 
Na medida em que o lazer é o "tempo disponível” a vontade do sujeito nesse tempo de direito também é permissiva, logo, é no tempo de lazer em que o sujeito encontra a possibilidade de escolher suas atividades e atribuir sentido para a sua existência para além dos condicionamentos sociais que imperam cotidianamente sobre ele. Ora, o sujeito pode fazer do lazer uma função para si, no sentido de descanso, divertimento, desenvolvimento intelectual, ético ou social.

Para benefício desse processo é indispensável a expressividade do sujeito da ação, isto é, a sua participação reflexiva na sua atitude no intento de transformar do “tempo disponível”, em um espaço reinventivo de si de maneira autônoma. Todavia, se o sujeito não se dispõe a pensar e a selecionar aquilo que pode contribuir para o seu desenvolvimento social e ético, o sentido e a escolha que por ele deveriam ser construídos, podem ser passíveis de influência dos meios de massa e modismos do mercado.

Podemos utilizar a conceituação da sequência vital (impulso, ato e satisfação) de Malinowski para entender essa problemática e a resposta do sujeito em relação aos estímulos midiáticos.

As propagandas produzidas por profissionais especializados na arte do convencimento propõem induzir o sujeito a um determinado desejo. As propagandas não vendem simplesmente produtos, mas também sonhos que nos aduzem a acreditar que podemos ser felizes quando fizermos um cruzeiro, se formos para uma "balada x" ou ainda se adquirirmos a roupa, o celular ou o carro do momento. Este desejo nascido no sujeito através dos estímulos imagéticos provocados pela mídia pode ser considerado um "impulso". Este impulso, que é desejo, para ser satisfeito necessita da adequação do sujeito ao padrão que está sendo anunciado ou mediante a aquisição do produto 
publicado. A compra desse produto ou a participação do sujeito em um evento ou viagem podem ser considerados o "ato" que consequentemente o leva a enganosa "satisfação" até que essa ideia caia em desuso e outra seja anunciada.

Esse processo fetichista pode ser caracterizado como uma espécie de sedução criada intencionalmente pelo mercado. Para tanto, o caminho entre impulso e satisfação é demarcado pelo imediatismo entre o sujeito e o objeto do desejo. Nesse sentido, esse “ato" quase mecânico e condicionante é o nó que aliena o sujeito à teia do consumo e à efemeridade das referências midiáticas. Isso porque, o prazer vivenciado pelo sujeito está intrinsecamente relacionado ao jogo do mercado e não a sua reflexão sobre si. Assim sendo, o sujeito passa a ser um fantoche, ou ainda um joguete que não flui por si mesmo a partir da sua própria escolha, mas através da ditadura visceral da lógica do consumo.

Em relação a Radcliffe-Brown cabe pensar a função intrinsicamente integrada à estrutura, já que é a função que permite a sua continuidade. Para o autor a definição de função segue a compreensão de Durkheim, portanto, remete consequentemente, a um modo padronizado de agir ou pensar relacionado com a estrutura social.

Transpondo a análise antropológica de Radcliffe-Brown para o nosso contexto social atual, podemos pensar que a estrutura social hegemônica é capitalismo. Nesta conjuntura o lazer como função deveria atender as imposições do mercado e seria um combustível para o motor da produção capitalista ou ainda um aparato funcional da própria gama ideológica do poder Estatal. Nesse sentido, o lazer alimentaria a lógica do consumo e a complacência da população em relação ao que tensiona as relações sociais e as relações de poder. Não possibilitando a ascensão do sujeito diante do seu conflito existencial, o lazer seria um instrumento de distração, amaciamento e domesticação. 
Natalia Puke e Nelson C. Marcellino Contribuições de Alguns Autores das Três das Principais Escolas...

Acerca dessas proposições o termo função anula a posição autônoma do sujeito em virtude da funcionalidade de uma estrutura pré-existente - e que embora o sujeito a componha -, favorece apenas o poderio de uma minoria que reina politica e economicamente em detrimento o esclarecimento dos indivíduos.

\subsection{O culturalismo e o lazer}

$\mathrm{Na}$ contramão dessas formas discursivas, mas dialogando e ampliando as concepções supracitadas, adentraremos a seguir na antropologia culturalista.

Também conhecida com particularismo histórico, a antropologia Culturalista é segundo Laplantine (2007), a abordagem mais abrangente em antropologia, visto que diz respeito a tudo que constitui uma sociedade, isto é, seus modos de produção, suas técnicas, sua organização política e jurídica, seus sistemas de parentesco, conhecimento, religião, língua, psicologia e artes. O seu interesse, entretanto, não é um levantamento sistemático desses aspectos, mas a maneira particular pela qual eles estão relacionados entre si.

O alemão naturalizado norte-americano Franz Uri Boas (1858 - 1942), é segundo Castro (2010), o principal representante do culturalismo. Sendo o primeiro a tratar a palavra cultura no plural, Boas rompeu drasticamente com o discurso evolucionista em antropologia, que por sua vez preconizava a homogeneidade das raças e apenas uma forma legítima de cultura.

Ainda segundo Castro (2010), Boas anuncia o que chamamos de etnociências e veio a ser responsável pela formação dos primeiros representantes da Antropologia Americana entre eles, Lowie, Kroeber, Sapir, Herskovitz, Linton e em seguida Ruth Benedict e Margareth Mead. 
No artigo "Os objetivos da pesquisa antropológica" publicado em 1932, Boas acentua que o objetivo da antropologia é "compreender os passos pelos quais o homem tornou-se aquilo que é biológica, psicológica e culturalmente" (BOAS, 2010, p. 88). Para efeito disso, é preciso, portanto, "investigar a vida mental do homem sobre um estudo da história das formas culturais e das inter-relações entre a vida mental individual e cultural" (BOAS, 2010, p. 97). Contudo, "os dados pré-históricos não nos dão a menor evidência sobre o desenvolvimento biológico da mente humana" (BOAS, 2010, p. 95), portanto, como reconstruir a história passada uma vez que o registro paleontológico é incompleto e além do mais, os aspectos mais importantes da cultura não deixam traços no solo, tais como a linguagem, organização social e religião?

Acerca dessa problemática, Boas reconhece que há muitas lacunas que limitam a pesquisa antropológica, por isso antropólogo deve se ater mais ao objetivo de entender os fenômenos individuais do que em estabelecer leis gerais, uma vez que não é um método seguro supor que todos os fenômenos culturais análogos estão historicamente relacionados.

No artigo "As limitações do método comparativo da antropologia", publicado anteriormente em 1896, Boas anuncia o método histórico em antropologia em contraposição ao discurso evolucionista. Segundo Boas,

O método histórico atingiu uma base mais sólida ao abandonar o princípio enganoso de supor conexões onde quer que se encontrem similaridades culturais. O método comparativo, não obstante tudo o que se vem escrevendo e dizendo ao seu louvor, tem sido estéril com relação aos resultados definitivos (BOAS, 2010, p. 38).

Embora Boas compartilhe da ideia que "a mente humana obedece às mesmas leis em todos os lugares" (BOAS, 2010, p. 29), e ainda, que "os mesmos fenômenos etnológicos devem-se sempre as mesmas causas", (BOAS, 2010, p. 29) uma vez que “os mesmos fenômenos ocorrem entre os mais diversos povos" (BOAS, 2010, p. 26), ele 
infere, entretanto, que "os mesmos fenômenos podem se desenvolver por uma multiplicidade de caminhos" (BOAS, 2010, p. 30).

Nesse sentido, o autor aponta que o que há de natural na espécie humana é a sua aptidão à variação cultural, portanto, o desenvolvimento histórico pode seguir cursos diversos, na medida em que ele seria o resultado das condições ambientais, dos fatores psicológicos e dos efeitos das conexões históricas das diversas culturas num dado tempo e espaço. Segundo suas palavras,

As ideias não existem de forma idêntica em toda parte: elas variam. Tem se acumulado material suficiente para mostrar que as causas dessas variações são tanto externas, isto é, baseadas no ambiente tomando o termo ambiente no seu sentido mais amplo -, quanto internas, isto é, fundadas sobre condições psicológicas. As influências dos fatores externos e internos sobre ideias elementares corporifica um grupo de leis que governa o desenvolvimento da cultura. Portanto, nossos esforços precisam ser direcionados no sentido de mostrar como tais fenômenos modificam essas ideias elementares (BOAS, 2010, p. 27)

Considerando o relativismo das manifestações culturais, Boas (2010) salienta a importância do trabalho de campo e o acesso à língua da cultura na qual se trabalha, visto que os costumes, os hábitos e atividades de uma da cultura só têm significado se forem relacionados o seu contexto particular. Embora as culturas possam apresentar similaridades em relação às outras, elas são extremamente diversificadas em suas manifestações de sentido e lógica internas de sobrevivência.

Segundo Laplantine (2007) a crítica de Boas em relação ao evolucionismo cultural não condena a teoria da evolução, mas sim, o método comparativo. Ora, como para Boas (2010), cada sociedade garante para si a estrutura de totalidade autônoma, não cabe compará-la a outra cultura ou ainda, estabelecer um status de inferioridade ou superioridade. 
Assim, Boas salienta que a postura do antropólogo, diante das manifestações culturais, deve tender mais para um observador do que para um investigador. Uma observação desprovida de juízos a priori, e sem expectativas formatadas por construções idearias ou românticas, possibilita o pesquisador compreender as especificidades e particularidades culturais de uma tribo, comunidade ou sociedade.

Outro representante do culturalismo antropológico é Clifford James Geertz (1926 - 2006). Considerado um dos principais expoentes da antropologia contemporânea, Geertz apresenta uma abordagem semiótica da cultura e defende que a antropologia é uma análise etnográfica densa e interpretativa.

No artigo "Uma descrição densa: Por uma teoria interpretativa da cultura" presente no livro "Interpretações das Culturas" de 1973, o autor desconstrói o valor absoluto de toda teoria, sobretudo porque, considera que os textos antropológicos tratam de "ficções, no sentido de "algo construído", algo modelado" (GEERTZ, 1989, p. 26). Isso não quer dizer que os textos antropológicos são falsos, mas são em primeira instância, "interpretações de segunda ou terceira mão" (GEERTZ, 1989, p. 25). Nesse sentido, ele aduz que toda a análise cultural é intrinsecamente incompleta, visto que “somente os nativos fazem uma interpretação de primeira mão" (GEERTZ, 1989, p. 39).

Geertz (1989) compreende que a antropologia social deve ser indispensavelmente etnográfica e por isso, consequentemente, requer uma descrição densa e exige um esforço intelectual e interpretativo de quem a faz. Segundo o autor, um relatório etnográfico pretende, portanto, esclarecer o que ocorre em tais lugares para reduzir a nossa perplexidade em relação as diferenças. De acordo com a sua leitura temos que indagar: “que tipo de homens são esses?” (GEERTZ, 1989, p. 26). 
No seu construto teórico há quatro características da descrição etnográfica: Ela é interpretativa; O que ela interpreta é o fluxo do discurso social; a interpretação envolvida consiste em tentar salvar o "dito" e fixá-lo em formas pesquisáveis; e por fim, a descrição é microscópica.

Considerando que os dados etnográficos são resultados da nossa própria construção a partir das construções de outras pessoas, não cabe a antropologia se preocupar com o status ontológico das coisas, mas sim interpretar e indagar qual é a importância das manifestações culturais.

A interpretação possibilita "um alargamento do universo do discurso humano" (GEERTZ, 1989, p. 24) e a teoria nesse sentido, deve "fornecer um vocabulário no qual possa ser expresso o que o ato simbólico tem a dizer sobre ele mesmo - isto é, sobre o papel da cultura na vida humana" (GEERTZ, 1989, p. 38).

Geertz (1989) critica as análises culturais preconizadas pelo idealismo, cognitivismo e pelo behaviorismo skinneriano, e adota em contraposição a essas perspectivas, o conceito de cultura a partir do campo semiótico. Tal como Max Weber, o autor acredita que "o homem é um animal amarrado a teias de significados que ele mesmo teceu" (GEERTZ, 1989, p. 15).

Mediante sua leitura a cultura seria uma dessas teias. A antropologia, portanto, não seria uma ciência experimental em busca de leis, mas uma ciência interpretativa à procura dos significados.

Desse modo, Geertz (1989) discorre que o trabalho da análise etnográfica é similar ao de um decifrador de códigos, ou ainda, semelhante ao um crítico literário, que pretende determinar a base social e a importância de uma dada obra. Nas suas palavras, 
emendas suspeitas e comentários tendenciosos, escrito não com sinais convencionais do som, mas como exemplos transitórios de comportamento modelado (GEERTZ, 1989, p. 20).

A análise semiótica compreende a cultura como um jogo de símbolos e o comportamento humano, como uma ação simbólica, isto é, que significa. Entretanto, não devemos nos preocupar tanto com os comportamentos, mas nos atentarmos a eles com exatidão, pois é "através do fluxo do comportamento - ou, mais precisamente, da ação social - que as formas culturais encontram articulação” (GEERTZ, 1989, p. 27).

Essa sua abordagem que pretende captar os significantes presentes no discurso social, ou seja, aquilo que está sendo transmitido com a ocorrência e através da agência do significado, está fundamentada no filósofo austríaco Wittgenstein, que por sua vez compreende a cultura como sistema entrelaçados de signos interpretáveis e representados pelo uso da linguagem.

Para Wittgenstein a linguagem é o limite do mundo humano e se refere a uma forma de vida na qual somos e conhecemos as coisas. É em consonância a essa leitura, que Geertz aponta a terceira característica da descrição etnográfica que diz respeito a tentativa de salvar "o dito" latente no fluxo do discurso social.

Acerca dessas proposições a cultura é um contexto que atém significados e a análise semiótica, portanto, possibilita um acesso às relações internas entre os elementos que organizam a estrutura simbólica da uma cultura. De modo geral, a abordagem semiótica da cultura auxilia-nos a ganhar acesso ao mundo conceptual, no qual vivemos, e estamos sujeitos.

Consequentemente, a análise semiótica permite através dos sistemas de conceitos que se "entrelaçam no corpo da etnografia, uma descrição minuciosa na 
esperança de tornar cientificamente eloquentes as simples ocorrências" (GEERTZ, 1989, p. 38).

A análise etnográfica deve considerar a especificidade complexa e a circunstancialidade das formas culturais, pois "a tarefa essencial da construção teórica não é codificar regularidades abstratas, mas tornar possível descrições minuciosas; não generalizar através dos casos, mas generalizar dentro deles" (GEERTZ, 1989, p. 36). Nesse sentido, concluímos com a quarta característica da análise etnográfica, que infere que ela é microscópica e tem como objetivo,

Tirar grandes conclusões a partir dos fatos pequenos, mas densamente entrelaçados; apoiar amplas afirmativas sobre o papel da cultura na construção da vida coletiva empenhando-as exatamente em especificações complexas (GEERTZ, 1989, p. 38)

Ao final do artigo Geertz (1989) acentua que a análise cultural tem que se precaver para não restringir sua abordagem a um esteticismo sociológico, pois,

É sempre presente o perigo de que a análise cultural perca de contato com as superfícies duras da vida - com as realidades estratificadoras políticas e econômicas, dentro das quais os homens são reprimidos em todos os lugares - e com as necessidades biológicas e físicas sobre as quais repousas essas superfícies (GEERTZ, 1989, p. 40)

Além de apontar essa problemática, ele assume que "comprometer-se com um conceito semiótico é comprometer-se com uma visão da afirmativa etnográfica como “essencialmente contestável"”" (GEERTZ, 1989, p. 39). Apesar disso, o autor conclui que,

A vocação essencial da antropologia interpretativa não é responder às nossas questões mais profundas, mas colocar à nossa disposição as respostas que outros deram - apascentando outros carneiros em outros vales - e assim incluí-las no registro de consultas sobre o que o homem falou (GEERTZ, 1989, p. 41)

O discurso culturalista traz significativas contribuições para os estudos do lazer.

Quanto a concepção cultural relativista de Franz Boas, podemos utilizá-la como um 
referencial metodológico para os projetos de políticas públicas e/ou instituições que desenvolvem ações de lazer em diversas e distintas comunidades e/ou cidades. Desse modo, cabe relembrar a problemática dos "pacotes de lazer" e da "difusão cultural" que foi abordada na passagem em que discorremos sobre a escola evolucionista.

Em primeiro lugar devemos nos questionar: O que irá definir um projeto de lazer em uma comunidade "x"? A partir de qual referencial e experiências os profissionais iram inserir um pacote de atividades ou até mesmo construir um espaço de recreação em uma dada localidade? Essas medidas têm sentido ou irão significar algo para a região que virá a usufruir desses espaços e ações?

Se Franz Boas pudesse responder uma dessas indagações, provavelmente ele diria que a definição e o referencial de um projeto cultural devem partir da própria lógica e vivência interna de uma dada comunidade. É por isso que ele acentuou a importância do acesso à língua da cultura na qual se trabalha, ao passo que o costume só tem significado se for relacionado com um contexto particular. Embora Boas considere que algumas ideias e fatos são universais, ele salienta que as "ideias diferem em conteúdo e significado, e por isso não podem ser tratadas como unidade” (BOAS, 2010, p. 107).

Nesse sentido, no que diz respeito ao lazer - cabe aos profissionais da área que desenvolvem ações culturais ou constroem espaços recreativos -, contatar empiricamente as localidades; não somente para metrar o espaço físico e conhecer as condições ambientais, mas sobretudo, para conhecer as especificidades internas e significados recorrentes entre as pessoas e por elas aspirados.

Essa abordagem requer competência e uma valorização dos conceitos de democracia e cidadania no seu real e amplo sentido. Doravante, seria imprescindível 
para os profissionais da área do lazer que estabelecessem um diálogo com os saberes inerentes as ciências humanas, na medida em que possibilitasse a esses profissionais uma compreensão mais ampla sobre tudo aquilo que constitui o ser humano. Seria indispensável um respeito às diferenças, as idiossincrasias e também o conhecimento da mentalidade sociológica dessas pessoas que compõem um dado espaço estudado. Isso pressupõe uma descrição densa e interpretativa, quase etnográfica, como propõe Geertz.

Para a teoria da interpretação de Geertz a cultura é um sistema de símbolos que em articulação produzem significados. Os significados suscitam no fluxo do discurso social de forma microscópica, por isso o antropólogo deve tentar salvar "o dito". O acesso a esse entrelaçado de símbolos só é possível quando em meio à circunstancialidade do acontecimento, ou seja, no contexto interno em que os significados recorrem e se atualizam em comportamentos.

Tendo em vista essas interpretações e transpondo essa perspectiva para os estudos do lazer - seria um grande ganho para os profissionais e departamentos públicos que atuam na área -, investirem na densidade dos projetos, no sentido de ampliar e dinamizar as ações que tenham sentido na conjuntura interna onde se vivenciam as práticas e atividades do lazer

Aplicando os pensamentos de Geertz, seria como trabalhar na investida interpretativa, mas tentando acima de tudo construir um lazer a partir do próprio autor da manifestação cultural. Isto porque, a espécie de material produzido por um trabalho de campo junto ao um grupo pessoas ou etnia, só pode adquirir atualidade sensível na medida em que possibilita "pensar não apenas realista e concretamente sobre eles, mas, o que é mais importante, criativa e imaginativamente com eles" (GEERTZ, 1989, pp. 33 - 34). 
O êxito do método culturalista para as ações concernentes ao lazer, necessita evidentemente do envolvimento popular em conjunto com as políticas públicas, isto é, a sua democratização. Para efeito disso, o profissional da educação física (que na maioria das vezes é quem assume os projetos relativos ao lazer) atuaria não simplesmente como um orientador das atividades corporais e recreativas, mas também, como um agente social e cultural que intui abarcar através do lazer, as múltiplas dimensões que constroem os indivíduos tanto enquanto cidadãos, tanto enquanto sujeitos.

Essas questões sobre a democratização do lazer a partir do envolvimento popular e do profissional da educação física como agente social e cultural explicitam mais uma complexa problemática que poderá ser discutida em outra oportunidade de pesquisa. Apesar disso, já seria um bom começo pensarmos o lazer particularmente como uma forma simbólica carregada de significados a serem interpretados. Essa leitura amplia o olhar sobre o conceito de lazer e possibilita o movimento do "querer saber mais" mesmo tendo em vista que o conhecimento pleno é impossível.

\section{Considerações finais}

Pensar o lazer é repensar de forma transversal e criativa as questões socioculturais e econômicas e, sobretudo, o humano para além dos papéis sociais que cerceiam a sua condição existencial. Assim, abordar o lazer mediante a antropologia é discutir também o "homem inteiro" na sua complexidade, determinações e, consequentemente, as possibilidades de "gêneses" dessa problemática ainda tão pouco explorada.

Analisar o discurso das escolas antropológicas ou de qualquer outro campo epistêmico é diagnosticar que todo saber é "poder" na medida em que instaura verdades, 
valores e padrões de comportamentos a serem reproduzidos no âmbito social e político. Nesse sentido, a análise das formas discursivas nos atenta ao "lugar" ao qual o conhecimento está construído e em suma, a sua intencionalidade que evidencia que nenhum saber é neutro. Pautada a nossa consciência em relação às intenções dos discursos, cabe-nos, portanto, assumindo que também estamos imersos em algum discurso, instrumentalizar as formas discursivas para compreender e esclarecer o objeto estudado, no intento de sempre e constantemente, ampliar as nossas perspectivas sobre as dimensões que constituem a cultura e natureza humana.

Como foi descrito no decorrer do artigo, percebemos que o discurso evolucionista pautado numa concepção progressista da história, relaciona-se com a perspectiva elitista do lazer, mas contribui também, para uma análise das políticas que desenvolvem o que chamamos de "pacotes de lazer" e "difusão cultural". Em relação ao funcionalismo pudemos observar que o lazer enquanto função pode ser um aparato instrumentalizado em benefício da lógica estrutural do capitalismo, mas em contrapartida, há a possibilidade de se pensar também, que essa funcionalidade pode ser re-significada "pelo" e "a partir" do próprio sujeito da ação. Enfim, acerca da perspectiva particularista e interpretativa presente no discurso cultural antropológico, percebemos a necessidade de compreender as especificidades culturais das diversas localidades e/ou comunidades que usufruem as políticas públicas concernentes ao lazer. Nesse sentido, concluímos, portanto, que o trabalho dos profissionais que atuam na área necessita de uma análise densa, no intento, de penetrar na vivência e no campo de significações dessas comunidades.

Ao analisar as formas discursivas não pretendemos estabelecer critérios valorativos, mas sim investigar a temática do lazer, possibilitando por fim, mesmo em 
meio às contradições que circundam os resultados, o aperfeiçoamento do universo do conhecimento que impulsiona a continuar a desbravar o próprio sentido do lazer.

\section{REFERÊNCIAS}

ARANHA, M. L. A. \& MARTINS, M. H. P. Filosofando: introdução à Filosofia. São Paulo: Moderna, 1991.

ABBAGNANO, Nicola. Dicionário de Filosofia. São Paulo: Martins Fontes, 2007.

BOAS, Franz. (1896 e 1920). "As limitações do método comparativo da antropologia" e "Os métodos da etnologia". In: CASTRO, Celso (Org.). Franz Boas. Antropologia Cultural. Rio de Janeiro: Jorge Zahar, 2010.

BRASIL. Constituição da República Federativa do Brasil de 1988. Disponível em: https://www.planalto.gov.br/ccivil_03/Constituicao/Constitui\%C3\%A7ao.htm. Acesso em: 18 out. 2011.

CASTRO, Celso. “Evolucionismo Cultural - Textos de Morgan, Tylor e Frazer”. Rio de Janeiro: Zahar, 2009.

Franz Boas - Antropologia Cultural. Rio de Janeiro, 2010.

CAVAllEIRO, M. C; SAlGADO M. Diadema: direito que vamos construindo. In: MARCEllino, N. C (Org.). Políticas Públicas Setoriais de Lazer. Campinas: Autores Associados, 1996.

CORBIN, Alain. Gritos e Cochichos. In: PERROT, Michelle (Org.). História da Vida Privada. Da Revolução Francesa à Primeira Guerra. São Paulo: Companhia das Letras, 1991.

COSTA, A. M. \& SCHWARCZ, L. M. Virando Séculos - No Tempo das Certezas (1890 - 1914). São Paulo: Companhia das Letras, 2000.

DELEUZE, Gilles. Nietzsche e a Filosofia. Rio de Janeiro: Ed. Rio, 1976.

HOUAISS. Dicionário Eletrônico 3.0. Editora Objetiva, 2009.

FAUSTO, Boris. Crime e Cotidiano - A Criminalidade em São Paulo (1880 -1924). São Paulo: Brasiliense, 1984.

FRAZER, James G. (1911). O Ramo de Ouro. Rio de Janeiro: Guanabara Koogan S.A, 1982.

(1908) "O escopo da Antropologia Social". In: Castro, Celso (Org.). Evolucionismo cultural. Rio de Janeiro: Zahar, 2009. 
GEERTZ. Clifford. "Uma Descrição Densa da Cultura". In: A Interpretação das Culturas. Rio de Janeiro: Guanabara Koogan, 1989.

JAPIASSÚ, H. \& MARCONDES, D. Dicionário básico de filosofia. Rio de Janeiro: Zahar, 2006.

LAPLANTINE, François. Aprender Antropologia. São Paulo: Brasiliense, 2007.

MALINOWSKI, Bronislaw. Uma Teoria Científica da Cultura. Rio de Janeiro: Zahar, 1970.

MARCELlinO, N. C. Estudos do Lazer - Uma Introdução. Campinas: Autores Associados, 2006.

"Lazer e Qualidade de Vida". In: MOREIRA, W. M. (Org.). Qualidade de Vida. São Paulo: Papirus, 2007.

. Lazer e educação. Campinas: Papirus, 2010.

Subsídios para uma política de lazer: o papel da administração municipal. In:

Revista Brasileira de Ciências do Esporte, v. 2I, n. 3, São Paulo, 1990.

MORGAN, Lewis H. (1877). A Sociedade Primitiva. Lisboa: Editorial Presença, 1973.

RADCLIFFE-BROWN, A. R. "Estrutura e função na sociedade primitiva". Petrópolis: Vozes, 1973.

WITTGENSTEIN, Ludwig. Investigações filosóficas. In: WITTGENSTEIN, Ludwig. Coleção os pensadores. São Paulo: Nova Cultural, 1996.

\section{Endereço dos Autores:}

Natalia Puke

Rua: Santo André, $\mathrm{n}^{\circ}$ 40, apto 43 - Jd. Elite

Piracicaba - SP - 13417-655

Endereço Eletrônico: napuke@gmail.com

Nelson Carvalho Marcellino

Rua 14 de dezembro, 428 apto.41

Campinas - SP - 13015-130

Endereço Eletrônico: marcelin@ @upernet.com.br 